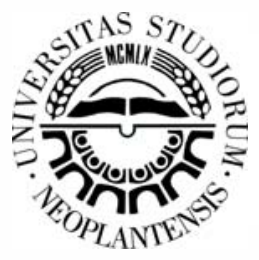

\title{
Determination of Velocity of Detonation Using Dautrich Method
}

\author{
Darko Šunjića*, Stipo Buljan ${ }^{b}$ \\ ${ }^{a}$ University of Mostar, Faculty of Mechanical Engineering, Computing and Electrical Engineering, Mostar, Bosnia and Herzegovina \\ ${ }^{b}$ Federal Ministry of Energy, Mining and Industry, Mostar, Bosnia and Herzegovina
}

\begin{abstract}
Explosive forming appeared at the end of the 19th century as unconventional technology that provides new methods to get workpieces with bigger dimensions and complex geometries. As a source of energy this technology uses explosives. Explosive, as such, is relatively inexpensive and theoretically with it, it is possible to get any amount of energy that is needed. Explosive forming is used with other technologies such as deep drawing, expansion of pipes, welding etc. One of the main explosive characteristics is the velocity of detonation that can be determined, inter alia, with the Dautrich method. This paper clarifies the method and gives a case study with explosive Vitezit 20.
\end{abstract}

Key words: Explosion; metal forming; velocity of detonation, Dautrich method.

\section{INIRODUCTION}

Explosion can be defined as a process in which a sudden transformation or energy release occurs. To characterize the process as an explosion the intensity of energy release is essential. For explosion, two parameters are important: the mount of released energy and time [1]. Explosions can be divided into physical, chemical and nuclear. In the case of physical explosion, energy is transforming from one form to another without changing the chemical composition. Nuclear explosions cause nuclear energy transformation in the heat through nuclear reactions and these are the most powerful explosive processes. Chemical explosions are the processes of transforming chemical energy into the heat through chemical processes, where the release of large amounts of heat is produced along generating large amounts of gases [2]. Chemical processes of decomposition of substance can be divided on combustion, deflagration and detonation. Detonation is a process of decomposition of substance at speeds above the speed of sound, apropos, from $1300 \mathrm{~m} / \mathrm{s}$ up to $10000 \mathrm{~m} / \mathrm{s}$. Substances that can be detonated are called high explosives. The speed of decomposition of an explosive substance in the detonating process is called velocity of detonation and presents the maximum rate of decomposition. Explosives are commonly divided into low (black powder) and high (TNT, dynamite) explosives [1]. They can provide, theoretically, any amount of energy that is needed for the process of metal forming. On the other hand, the problem is in controlling of such suddenly released work so that we get the desired shape [3].

\section{APPUCATION OF EXPLOSIVE IN METAL FORMNG TECHNOLOGIES}

Metal forming technologies include all technologies that give the material desired shape and dimensions with the plastic deformation. These methods represent a very complex area in engineering practice which solutions requires an enormous effort from constructors to technologists. Today, it is still one of the most common processing technology, especially in air and car industry. Development of computers and product design software enabled product optimization. The results were new workpieces that were economically unjustified and even impossible to create with conventional methods. Thus, a number of new unconventional technologies have been developed, that enable modern requirements and processing of materials that could not be formed with conventional technologies. One of these unconventional technologies is explosive forming, which include in highenergy rate forming. This technology is used for deep drawing, expansions of tubes, for cutting, welding, increasing hardness, etc. $[5,6]$. The most common method of explosive forming is deep drawing as shown in Figure 1.

* Corresponding author's.e-mail: darko.sunjic@fsre.sum.ba 


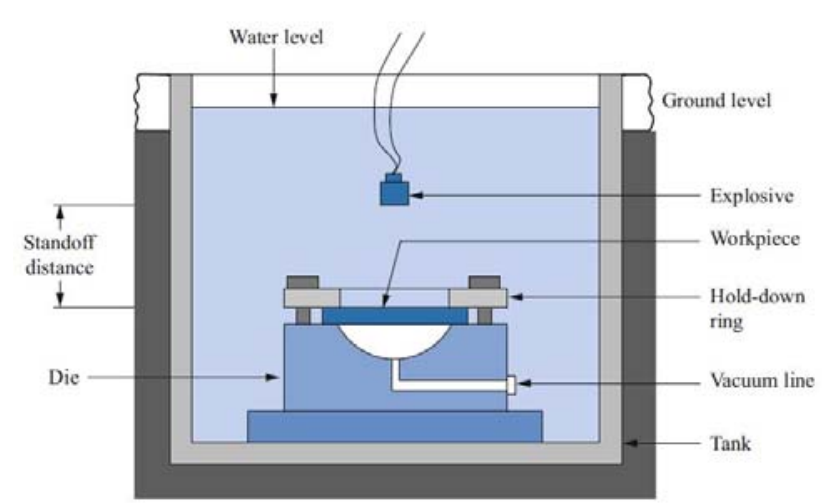

Fig. 1 Deep drawing with explosion [7]

The workpiece on which the hold-down ring is mounted is placed on the die. Above the workpiece, an explosive is placed at a certain height. Certain conditions regarding the height of the water above the explosives must be fulfilled. The workpiece is immersed in a water tank with die and explosion is initiated. During the explosion, a certain amount of energy is released and goes to the environment. Part of this energy is delivered to the workpiece and it is used on its deformation. In this kind of forming it is necessary to ensure that the impact on the die is as small as possible, and that can be ensured placing rubber underneath the die. It is also necessary to consider the height of the explosive charge above the workpiece because increasing the height increases the amount of explosives. Water is commonly used as a medium in the process of deep drawing with explosion because it is available and cheap. Furthermore, oil, sand, rubber, metal balls and air can be used. By replacing water as a medium after the air, the mass of explosive deceased by $80 \%$ [8].

\section{DEIERMNATION OF VECOCTY OF DETONATION- CASESTUDY}

To determine velocity of detonation it requires test tubes, lead plate, steel plate, detonator and cord [9]. Explosive for testing is placed in the test tube and needs to be in contact within the tube. The length of the explosive charge in the test tube between the openings is called the measuring length of the explosive charge. The distance between measuring length and detonator should be approximately $100 \mathrm{~mm}$ for powder explosives and $200 \mathrm{~mm}$ for water gel explosives. It is necessary to prepare two cords of exactly specified detonation velocity, one of which is longer $(900 \mathrm{~mm})$ and other shorter $(600 \mathrm{~mm})$. The ends of cords are placed side by side and the other ends are pulled in openings in test tube into explosive charge. Longer end of the cord must be closer to the detonator. The attached ends of cords are places on lead plate and lead plate is placed on steel plate. The process setup scheme is shown in Figure 2.

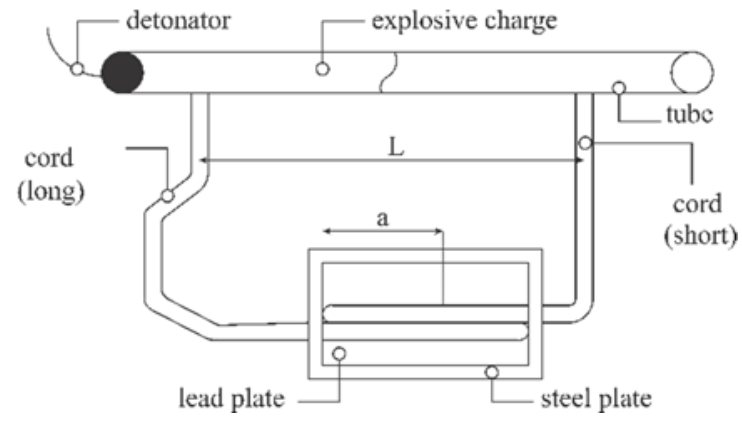

Fig. 2 Dautrich method

When everything is prepared, test tube with explosion is put into the ground or sand. The plates should be as far from the explosive as it possible, and cords must be ground-in in the form of sinuosity to avoid sharp corners. The initiation of detonator is done electrically or by slow burning cord. When the detonation wave reaches the longer cord it will transfer on it. On its further way as it passes through the explosive tube, the detonation wave will come to the shorter cord that will also detonate. The collision of detonation waves of two cords will create a notch on the lead.

After detonation, the distance to the notch needs to be measured and the required velocity of detonation of the explosive is calculated according to the following equation:

$$
V_{E}=\frac{v \cdot L}{2 a}
$$

where $V_{E}$ represent calculated velocity of detonation in $\mathrm{m} / \mathrm{s}, \mathrm{L}$ is measuring length of explosive charge in $\mathrm{mm}$, and $\mathrm{v}$ is standard velocity of detonation of cords in $\mathrm{m} / \mathrm{s}$.

The test is performed three times and as result the medium value is taken. First testing was with plastic explosive Vitezit 20, shown in Figure 3. A seamless tube, $28 \mathrm{~mm}$ in diameter and length of $500 \mathrm{~mm}$, was used.

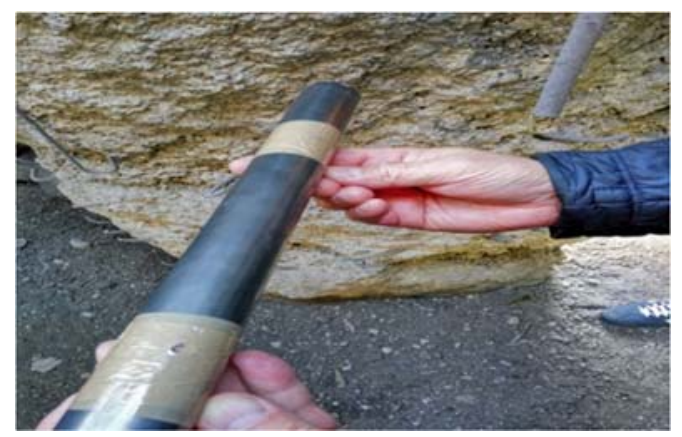

Fig. 3 Explosive Vitezit 20

The distance between two cords is $200 \mathrm{~mm}$ and velocity of detonation of cords is standard, $6000 \mathrm{~m} / \mathrm{s}$. Explosive with cords is shown in Figure 4 and on Figure 5 is explosive with detonator and cords. 


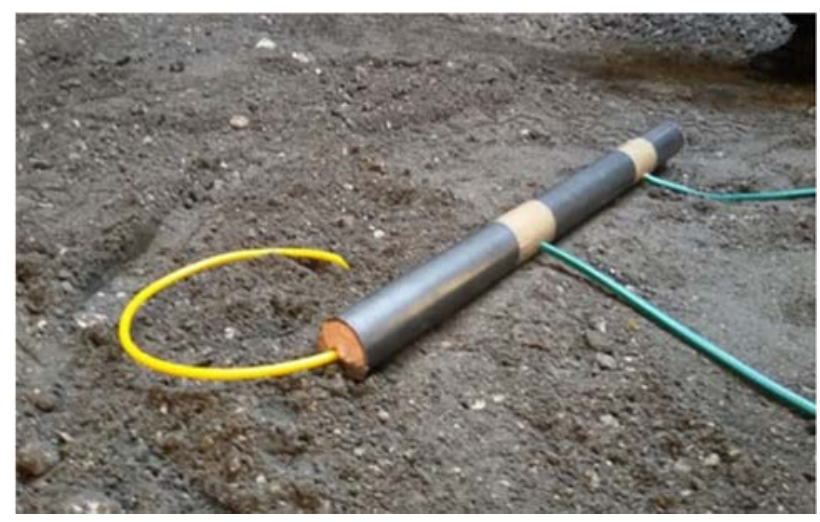

Fig. 4 Explosive with cords

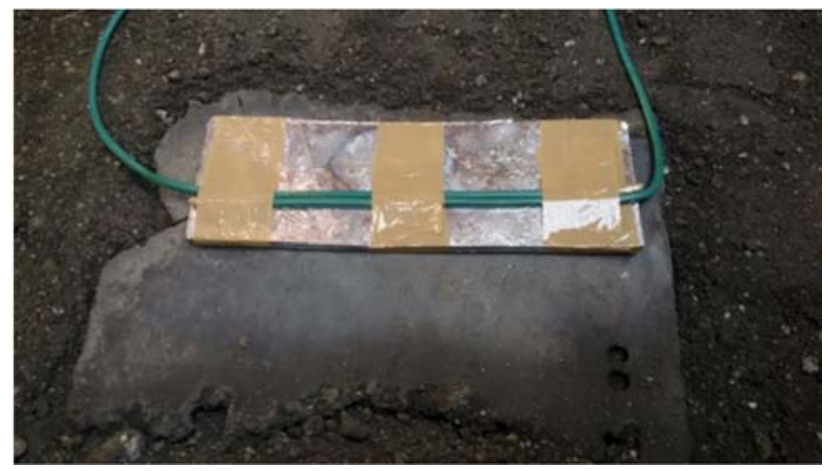

Fig. $\mathbf{L}$ Lead and steel plate

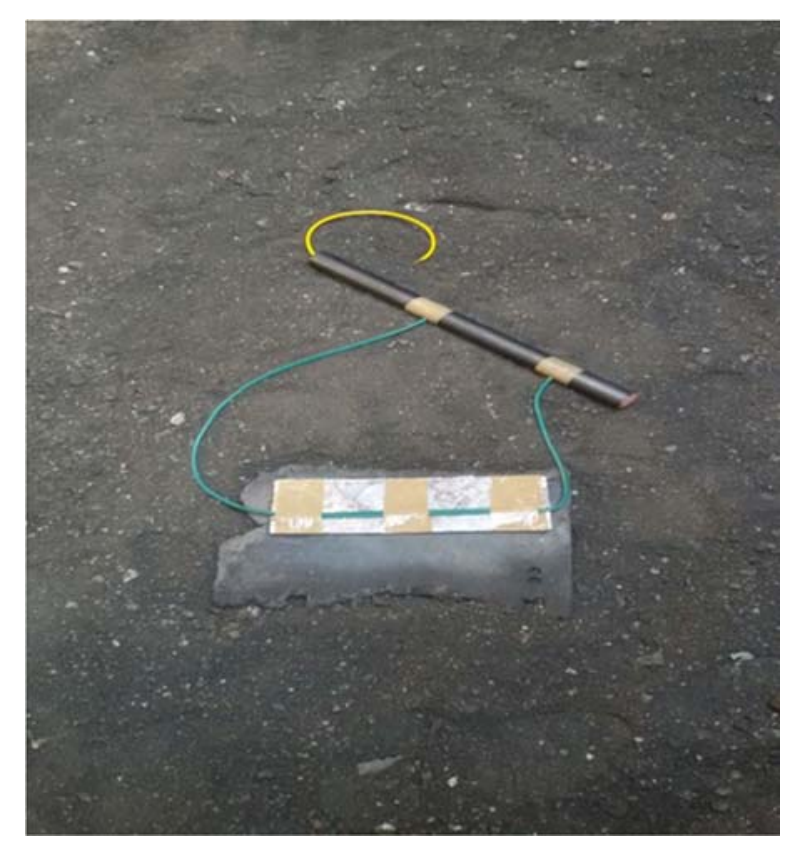

Fig. 6 A prepared detonation scheme

Figure 6 shows prepared detonation scheme. The diameter of the openings in which longer and shorter cords are pulled in is $7 \mathrm{~mm}$. The length of the slow-burning cord, which is used as detonator, is $30 \mathrm{~mm}$ and it takes approximately 30 seconds to create impact on explosive. After the test is completed, distance of the formed notch is measured from the end of the plate and it is $120 \mathrm{~mm}$. Formed notch is shown in Figure 7.

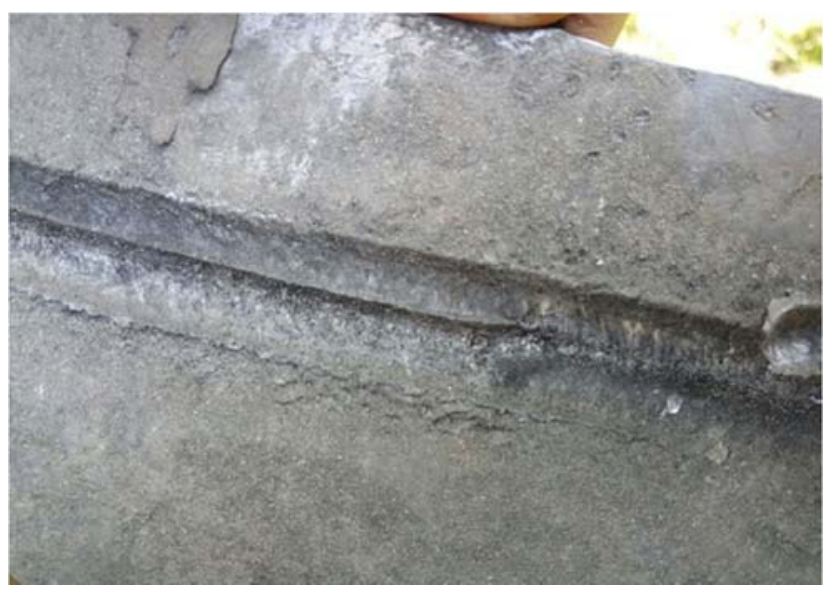

Fig. 7 Formed notch after the detonation

According to (1) velocity of detonation is calculated and it is $5000 \mathrm{~m} / \mathrm{s}$. Another testing was carried out using powder explosive, Amonex 1. The length of the tube was $200 \mathrm{~mm}$ and the distance between cords was $100 \mathrm{~mm}$. The diameter of tube was $30 \mathrm{~mm}$. Fig. 8. shows this testing where right cord represents start and left cord represents the end of explosion.

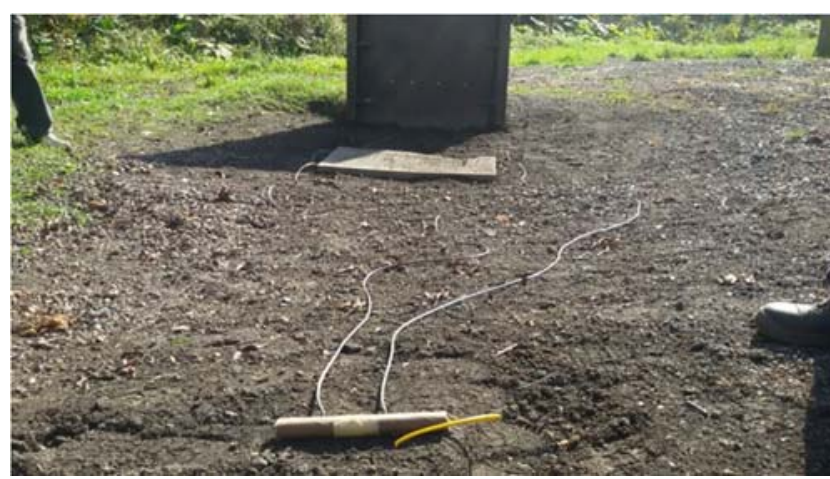

Fig. 8 Powder explosive

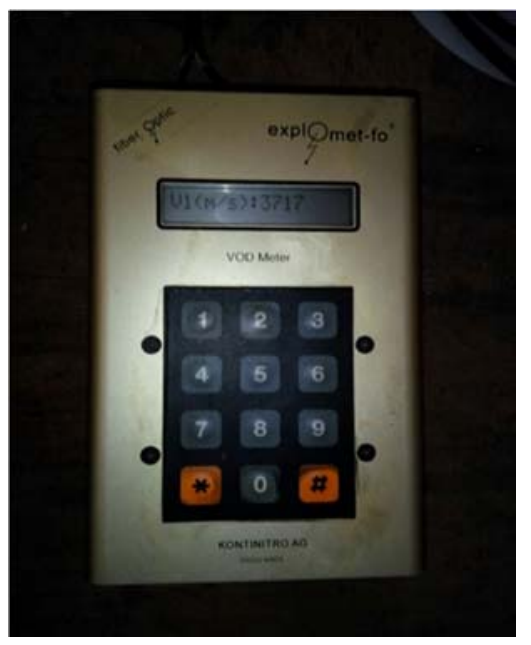

Fig. 9 Electronic clock for measuring of velocity of detonation

As it shown in Fig. 9. velocity of detonation of powder explosive Amonex 1 is $3717 \mathrm{~m} / \mathrm{s}$. 


\section{CONCLUSION}

The velocity of detonation is one of the most important characteristics of explosive because it can determine the quality of explosive. If the workpiece is not correctly deformed, it can be checked whether the problem is with the explosive by measuring the velocity of detonation. If the velocity of detonation is much lower than velocity prescribed by the manufacturer, it shows that the quality of explosive is not within the standard.

The velocity of detonation of plastic explosive Vitezit 20 and powder explosive Amonex 1 is tested in the paper. Both explosives show standard quality shown by the manufacturer which is tested using the Dautrich method.

\section{ACKNOMFDGMENTS}

The authors want to thank firm Vitezit for the equipment, material and help during the experiment.

Part of the paper is from magister thesis of Marko Raič.

\section{REFERENCES}

[1] Meyer R., Köhler J., Homburg A. (2007). Explosives, Sixth Completely Revised Edition.
Wiley-VCH Verlag GmbH, Weinheim

[2] Savić M. (1998). Miniranje na površinskim kopovima. RTB, Institut za bakar.

[3] Šunjić D., Buljan S. (2018) "Application of Explosives in Metal Forming," International Conference "New Technologies, Development and Applications", pp. 144-148.

[4] Mynors D.J.,Zhang B. (2002). Applications and capabilities of explosive forming. Journal of Materials Processing Technology. 125-126, no. March, pp. 1-25, DOI: 10.1016/S09240136(02)00413-2

[5] Bohanek V., Dobrilović M., Škrlec V. (2013) Primjena energije eksploziva pri obradi metala. Rudarsko-geološko-naftni zbornik. 26, pp. 29-37.

[6] Altan T., Tekkaya A.E., (2012). Sheet metal forming: processes and applications. ASM international

[7] Bhaduri A. (2018) Mechanical Properties and Working of Metals and Alloys. 264. Springer

[8] Buljan S. (2007). Primjena genetskih i stohastičkih metoda u istraživanju procesa dubokog vučenja eksplozijom, disertacija, Fakultet strojarstva i računarstva, Mostar

[9] Suceska M. (2012). Test methods for explosives. Springer Science \& Business Media. 